\title{
SPERM DNA INTEGRITY TEST AND ASSISTED REPRODUCTIVE TECHNOLOGY (ART) OUTCOME
}

\section{Violeta S. Rilcheva, Nina P. Ayvazova ${ }^{1}$, Lyubomira O. Ilieva', Svetlana P. Ivanova', Emiliana I. Konova ${ }^{2}$}

MC Clinical Institute for Reproductive Medicine-Pleven

${ }^{1}$ Institute of Biology and Immunology of Reproduction, Sofia

${ }^{2}$ Center for Reproductive Health, Medical University - Pleven

\section{Corresponding Author:}

Violeta S. Rilcheva 20, Skobelevblvd.

Pleven, 5800

Bulgaria

e-mail:dr.rilcheva@gmail.com

Received: May 14, 2015

Revision received: October 22, 2015

Accepted: May 30, 2016

\section{Summary}

The objective of the study was to investigate the influence of sperm DNA fragmentation index (DFI) by DNA integrity test on pregnancy outcome and pregnancy loss after assisted reproductive technology (ART) procedure: autologous intracytoplasmic sperm injection (ICSI), donation eggs ICSI, and intrauterine insemination (IUI). We investigated men from 531 couples undergoing autologous ICSI procedure $(\mathrm{n}=416)$, from couples undergoing donation eggs procedure $(\mathrm{n}=39)$ and IUI $(\mathrm{n}=76)$. We performed the following interventions: semen analysis, DNA integrity test, embryo scoring by Gardner and Schoolcraft grading system (1999). The study showed no statistically significant differences between the group regarding pregnancy rate $\left(\chi^{2}=0.55 ; \mathrm{p}>0.05 ; \mathrm{OR}=1.25\right.$, $95 \%$ CI 1.23-1.46; $>>0.05$ ). However, with increased levels of DFI, the number of pregnancy losses became higher (including biochemical pregnancies and spontaneous abortions) at $\mathrm{OR}=5.65(95 \% \mathrm{CI} 4.32-7.11$; $\mathrm{p}=0.05)$. We examined the percentage of grade I blastocysts (by Gardner and Schoolcraft, 1999) before donation eggs embryo transfer and found a statistically significant correlation with both the DFI $\left(\chi^{2}=7.80\right.$; $\mathrm{p}<0.05)$ and sperm morphology $\left(\chi^{2}=6.14 ; \mathrm{p}<0.05\right)$. Analysis of the relationship between DFI and IUI output (clinical pregnancy, miscarriage) revealed significant correlations in both directions: between DFI and pregnancy rate after IUI $\left(\chi^{2}=6.29 ; p<0.05\right)$ and between the DFI and pregnancy development after IUI $\left(\chi^{2}=6.87\right.$; $\mathrm{p}<0.05$ ). The three group categories (autologous, heterologous ICSI procedures and IUI) studied showed that sperm samples with DFI $>27 \%$ were associated with increased risk of early pregnancy loss. Men with infertility should undergo DNA fragmentation assay in addition to the standard semen analysis. When DFI exceeds $27 \%$, ICSI should be a method of choice, even in cases where the conventional parameters of semen analysis tests are normal.

Key words: sperm DNA fragmentation, male infertility, ICSI, pregnancy rate, pregnancy loss

\section{Introduction}

The male factor is one of the most common causes of infertility, assuming that defects in sperm account for $30 \%$ to $50 \%$ of clinical cases of infertility [1-3]. Sperm abnormalities, including decreased sperm concentration and motility, and abnormal sperm 
morphology forms, lead to reduced likelihood to achieve natural pregnancy. Before 1992, severe abnormalities of sperm parameters were not fully addressed by current procedures for treatment of infertility as intrauterine insemination (IUI) and conventional in vitro fertilization (IVF) procedure. The establishment of intracytoplasmic sperm injection (ICSI) in 1992 revolutionized the treatment of male infertility, allowing males with a single living sperm, regardless of other parameters, to become candidates for treatment of infertility [4]. However, in many clinics, using ICSI, the outcome of the procedures is below expectations. The first reports appeared on higher success rate of surgical procedures with extracted sperm [5, 6], and the lack of correlation between conventional sperm parameters. Unsuccessful ICSI cycles became the focus of debate for reproductive specialists.

In clinical practice, the etiology of unsuccessful ICSI cycles is most often associated with the female partner's age [7], regardless of sperm parameters. Therefore, many couples, failing to complete the assisted reproductive technology (ART) procedure are offered egg donation. The development of abnormal embryos [6] and blastocysts is associated with abnormal sperm parameters [8-11]. Results from assessment of sperm DNA fragmentation (DFI) by analyzing sperm chromatin structure (DNA Integrity test), have impact on both natural pregnancy $[10,11]$ and that achieved through ART. Pilot studies have shown that high levels of DNA fragmentation (DFI $>27 \%$ ) decrease fertility potential in patients undergoing ART procedure [12], even in men with completely normal standard sperm parameters [13]. Therefore, the lack of correlation between conventional parameters of sperm and DNA fragmentation $[5,9,14,15]$ determine DNA fragmentation as a potential source of male infertility in normozoospermic men. That is why further evaluation of sperm DNA fragmentation is required in the study of male infertility [16].

\section{Materials and Methods}

\section{Subject selection}

The study was based on a cohort of consecutive infertile couples undergoing ART at the centre for ART procedure (Medical Center Clinical Institute for Reproductive Medicine - Pleven, Bulgaria), during the period January 2010 -
December 2014. A total number of 531 ART procedures: 416 autologous ICSI cycles, 39 donation egg procedures, and 76 IUI procedures (28 donor sperm procedures and 48 autologous IUI procedures) were included. The inclusion criteria for the female partners were baseline follicle-stimulating hormone (b-FSH) $<12.5$ IU/1 for both autologous procedures.

\section{Semen collection and preparation}

Semen sample were collected by masturbation after 3 to 7 days of sexual abstinence. After complete liquefaction at $36.6 \mathrm{C}^{\circ}$ for 30 minutes, 5 $\mu \mathrm{L}$ of each sample was loaded in an improved Neubauer counting chamber (Marienfeld Superior, Germany) where conventional sperm analysis of concentration was carried out. Morphology was assessed according to strict Kruger criteria, and motility was measured. All results were classified according to the World Health Organization(WHO) 2010 criteria [17].

\section{DNA integrity test}

Sperm DNA damage was evaluated by flow cytometry after staining with acridine orange. On the day of analysis, the samples were defrosted and immediately tested. All buffers and samples were kept at 4 to $6 \mathrm{C}^{\circ}$ and the test was performed in a box with ice. After washing with TNE $(0.15 \mathrm{M}$ NaCL, 0.01M TrisHCL, 1mM EDTA, pH 7.4) buffer, the sperm concentration was adjusted to approximately $1-2 \times 106$ cells $/ \mathrm{ml}$ and $200 \mu \mathrm{L}$ of the sample was placed in $12 \times 75$ flow cytometry test tubes. After that, $400 \mu 1$ of low-pH (pH 1.2) detergent solution containing $0.1 \%$ Triton X-100, $0.15 \mathrm{M} \mathrm{NaCl}$ and $0.08 \mathrm{M} \mathrm{HCl}$ was added for 30 sec., immediately followed by $1.2 \mathrm{ml}$ staining buffer (phosphate-citrate buffer, $\mathrm{pH}$ 6.0) with 6 $\mathrm{mg} / \mathrm{l}$ acridine orange (AO, chromatographically purified; Sigma-Aldrich, USA). The cells acquired were analysed using a FACScan flow cytometer (Becton Dickinson). A total of 5000 events were accumulated for each measurement at a low flow rate. A $488 \mathrm{~nm}$ light source was used. The study of the sperm chromatin was based on the properties of metachromatic AO staining. Acridine orange emited green light upon binding to double-stranded DNA (native) and red light when binding to a single-stranded DNA. Data was analyzed by FlowJo software (TreeStar, Inc, Ashland, OR). Computer gates were used to determine the proportion of spermatozoa with increased levels of red and green fluorescence. The results were presented as DNA 
fragmentation index (DFI), high DNA stainability (HDS).

\section{ART procedures \\ ICSI}

Oocytes for recombinant FSH (rec-FSH - Gonal F, Merck Serono; Puregon, Organon) were retrieved from women after ovarian stimulation for 7-11 days. When at least one follicle reached a diameter $>18 \mathrm{~mm}, 10000 \mathrm{IU}$ of human chorionic gonadotropin (hCG - Pregnyl, Organon) was administered to induce follicle maturation. Extraction of eggs was performed 36 hours later under vaginal ultrasound control by follicle aspiration.

\section{IUI}

Fallopian tubes patency was proved by either hysterosalpingography (HSG) or laparoscopy. Female patients were stimulated by clomiphene citrate (Clostilbegyt) for 5 days and human menopausal gonadotropin (hMG, Merional) 75 IU of day $8 \pm 3$ for 4 days.

When two or more follicles measured more than $18 \mathrm{~mm}, 10000 \mathrm{IU} \mathrm{hCG}$ (Choriomon, Pregnyl) was applied to stimulate follicular maturation. After 36 hours, a raw semen sample treated by the double-density gradient method was prepared. The procedure for washing and dilution was performed under Supra Sperm media (Origio) and $1 \mathrm{ml}$ aliquot of this sperm sample was used for insemination.

\section{Pregnancy outcomes}

A biochemical pregnancy (BP) was defined as a plasma $\beta$-hCG concentration of $>5 \mathrm{IU} / 1,14$ days after embryo transfer (ET). A clinical pregnancy (CP) was defined as the presence of gestational sac detected by ultrasound and with a heartbeat 3 weeks after a positive result from a $\beta$-hCG test. Pregnancy loss was defined as miscarriage before gestation week 12.

\section{Embryos scoring}

The Gardner and Schoolcraft (1999) grading system was used to evaluate blastocysts expansion. A grade 1 blastocyst was assumed to have a blastocoel cavity of less than half of the volume of the embryo.

\section{Statistical analysis}

Statistical analysis was performed using Statgraphics plus 2.1 software for Windows. The data are presented as mean \pm standard deviation (mean $\pm \mathrm{SD}$ ). Statistical significance was set at $\mathrm{p} \leqslant 0.05$.

\section{Results}

\section{ICSI procedure}

We investigated data of 416 couples undergoing autologous ICSI procedure and 39 couples undergoing donation eggs procedure. In the first group, the males' mean age range was $35.16 \pm 5.7$ years, and that of the female partners was $34.42 \pm 4.24$ years. We registered 189 positive pregnancy tests and 227 negative tests on day 14 after ET. The pregnancy rate outcome was $45.4 \%$ (Table 1).

The female patients were grouped according to age and the pregnancy rate was registered for each group. Results were as follows: group 1 - 61 patients, age $<29$ years, pregnancy rate $52.46 \%$; group $2-179$ patients, age range $30-35$ years, pregnancy rate $48 \%$; group $3-122$ patients, age range $35-40$, pregnancy rate $46.7 \%$; and group $4-$ 53 patients, age $40-43$ with a pregnancy rate $13 \%$.

Regarding the pregnancy loss after a positive test on day 14 after ET, we registered 122 clinical pregnancies with delivery (67. 4\%). Pregnancy loss was registered in 59 women - $24 \mathrm{BP}(3.2 \%)$ and 35 missed abortions (19.4\%).

Regarding DFI, the patients were divided into two groups depending on the cut-off value of DFI $(27 \%)$. No statistically significant difference was seen between the DFI value and the pregnancy rate $\left(\chi^{2}=0.55 ; \mathrm{p}>0.05 ; \mathrm{OR}=1.25 ; 95 \%\right.$ CI 1.23 1.46).

Increased values of DFI were associated with higher rates of pregnancy loss $(\mathrm{OR}=5.65 ; 95 \% \mathrm{CI}$ 4.32-7.11; $\mathrm{p}<0.05)$, including biochemical pregnancies and spontaneous abortions (SPA). In the group of $\mathrm{DFI}<27 \%$, the pregnancy loss rate was $27 \%(14 \% \mathrm{BP} ; 13 \% \mathrm{SPA})$, while in the group of DFI $>27 \%$, the pregnancy loss rate was twice as high $(63 \%)$.

To evaluate the embryo quality, we used the scoring system of Gardner and Schoolcraft. According to that system, the cut-off value of grade I blastocyst is $40 \%$. Two groups were formed according to this value, above and below a value of $40 \%$, respectively, and the DFI values for paternal spermatozoa in the two groups were compared. From sperm with normal DNA fragmentation, $87.23 \%$ of embryos were obtained, and of these, $64.6 \%$ were classified as grade I quality, and $35.4 \%$ were of low quality. 
Table 1. Comparison of couple characteristics (data from 531 ART procedures), sperm parameters, DNA damage, embryo quality and pregnancy outcome between pregnant and non-pregnant couples by cycle type (IUI, ICSI and donation egg ICSI)

\begin{tabular}{|c|c|c|c|c|c|c|}
\hline & \multicolumn{2}{|c|}{ IUI } & \multicolumn{2}{|c|}{ ICSI } & \multicolumn{2}{|c|}{ Donation egg ICSI } \\
\hline & Pregnant & $\begin{array}{l}\text { Not } \\
\text { Pregnant }\end{array}$ & Pregnant & $\begin{array}{l}\text { Not } \\
\text { Pregnant }\end{array}$ & Pregnant & $\begin{array}{l}\text { Not } \\
\text { Pregnant }\end{array}$ \\
\hline Cycles included (n) & 14 & 62 & 189 & 227 & 15 & 24 \\
\hline Male age (years) & $31.05 \pm 7.3$ & $44 \pm 5.5$ & $35.3 \pm 5.7$ & $36.2 \pm 5.8$ & - & - \\
\hline $\begin{array}{l}\text { Sperm concentration } \\
(\text { million } / \mathrm{ml})\end{array}$ & $68.85 \pm 24.4$ & $27.17 \pm 1.59$ & $50.79 \pm 3.4$ & $48.25 \pm 4.48$ & $59.4 \pm 5.6$ & $51 \pm 5.6$ \\
\hline Progressive motility $(a+b, \%)$ & $55.79 \pm 18.7$ & $52.33 \pm 20.4$ & $39.9 \pm 9.6$ & $41.6 \pm 11.6$ & $45.6 \pm 5.6$ & $43.5 \pm 5.6$ \\
\hline $\begin{array}{l}\text { Sperm morphology (normal } \\
\text { forms, \%) }\end{array}$ & - & - & $3.7 \pm 2.03$ & $3.4 \pm 2.4$ & $3.6 \pm 5.6$ & $3.2 \pm 5.6$ \\
\hline DFI $(\%)$ & $8.86 \pm 7.14$ & $15.09 \pm 9.4$ & $14.18 \pm 8.9$ & $15.85 \pm 10.12$ & $16.69 \pm 5.6$ & $15.34 \pm 5.6$ \\
\hline $\operatorname{HDS}(\%)$ & $5.85 \pm 3.01$ & $9.65 \pm 2.99$ & $10.7 \pm 6.62$ & $11.4 \pm 5.08$ & $7.35 \pm 5.6$ & $7.72 \pm 5.6$ \\
\hline Female age (years) & $32.7 \pm 7.3$ & $36.5 \pm 7.2$ & $33.7 \pm 3.8$ & $35.3 \pm 4.48$ & $41 \pm 5.6$ & $45.2 \pm 5.22$ \\
\hline Oocytes retrieve $(\mathrm{n})$ & - & - & 15.94 & 12.5 & $21 \pm 5.6$ & $18 \pm 5.6$ \\
\hline Blastocysts grade I (\%) & - & - & $68 \pm 24.8$ & $66.7 \pm 27$ & $65 \pm 5.6$ & $54 \pm 5.6$ \\
\hline Pregnancy rate $(\%)$ & 18.8 & - & 45.4 & - & 55.2 & - \\
\hline
\end{tabular}

The distribution in the embryos group, obtained from sperm cells with DFI $>27 \%$ was similar: $54.7 \%$ of blastocysts were classified as good quality embryos. No statistically significant difference was found for the DFI of the paternal spermatozoa in the two groups ( $p>0.05)$.

The highest percentage of high-quality embryos $(72.13 \%)$ were observed in the female age group below 29 years. This percentage was $65.4 \%$ in the group with age range $30-35$ years, and in the 36-40 and over 40 age groups it was $57.02 \%$ and $63.3 \%$, respectively. In this distribution, we found a weak correlation between the age of female patients and embryo quality $\left(\chi^{2}=4.64 ; \mathrm{r}=0.10 ; \mathrm{p}<0.05\right)$. This suggests that it was not the age of females that determined the embryo quality but rather the cause of infertility and the stimulation procedure protocol. After using long-down stimulation protocol, the mean number of the eggs retrieved was 13.5 eggs per patient $(\mathrm{SD} \pm 9.8)$. The age distribution of females is shown on Table 2 .
We found a statistically significant relationship between the number of oocytes, obtained after stimulation and the age of the patient $\left(\chi^{2}=22.8 ; \mathrm{p}<0.001\right)$, as well as between the number of oocytes per female and pregnancy outcome $\left(\chi^{2}=10.62 ; \mathrm{p}<0.05 ;\right.$ Table 3$)$.

A statistically significant correlation between sperm morphology and pregnancy outcome after ICSI procedure was not found $\left(\chi^{2}=0.46 ; p>0.05\right)$, nor was a correlation found with the occurrence of spontaneous abortions after ART $\left(\chi^{2}=2.47\right.$; $\mathrm{p}>0.05)$.

This study found statistically significant correlation $\left(\chi^{2}=12.19 ; \mathrm{p}<0.05\right)$ between sperm morphology and DFI. The distribution between DFI and sperm morphology is shown on Table 4.

Regarding sperm motility, a weak statistical dependence on DFI was found $\left(\chi^{2}=2.47 ; p<0.05\right)$. The distribution between DFI and sperm progressive motility is shown on Table 5 .

Table 2. Distribution between female age and number of retrieved eggs by ICSI procedure

\begin{tabular}{|c|c|c|c|c|}
\hline$\overline{E g g s}(\mathrm{n})$ & $<10$ & $10-15$ & $>15$ & Total \\
\hline \multicolumn{5}{|l|}{ Female age } \\
\hline$<29$ years & $6.28 \%$ & $1.21 \%$ & $7.25 \%$ & $14.73 \%$ \\
\hline $30-35$ years & 18.85 & $10.63 \%$ & $13,74 \%$ & $43.24 \%$ \\
\hline $36-40$ years & $14.2 \%$ & $5.50 \%$ & $9.42 \%$ & $29.23 \%$ \\
\hline$>40$ years & $8.94 \%$ & $1.45 \%$ & $2.42 \%$ & $12.80 \%$ \\
\hline Total & $48.31 \%$ & $18.84 \%$ & $32.82 \%$ & $100 \%$ \\
\hline
\end{tabular}


Table 3. Distribution between the number of eggs per female and pregnancy outcome after ICSI

\begin{tabular}{|c|c|c|c|}
\hline $\begin{array}{ll}\text { Eggs/female } & \text { Pregnancy outcome } \\
\end{array}$ & Pregnant & Not pregnant & Total \\
\hline$<10$ & $18.07 \%$ & $30.12 \%$ & $48.19 \%$ \\
\hline $10-15$ & $9.4 \%$ & $9.4 \%$ & $18.8 \%$ \\
\hline$>15$ & $18.07 \%$ & $14.94 \%$ & $33.01 \%$ \\
\hline Total & $45.54 \%$ & $54.46 \%$ & $100 \%$ \\
\hline
\end{tabular}

Table 4. Distribution between DFI and sperm morphology (ICSI procedure)

\begin{tabular}{|c|c|c|c|}
\hline $\begin{array}{lll}\text { DFI }(\%) & \text { Morphology } & \text { (normal forms, \%) }\end{array}$ & $>4 \%$ & $0-3 \%$ & Total \\
\hline$<26.9 \%$ & $41.35 \%$ & $45.67 \%$ & $87.02 \%$ \\
\hline$>27 \%$ & $2.88 \%$ & $10.1 \%$ & $12.98 \%$ \\
\hline Total & $45.23 \%$ & $54.77 \%$ & $100 \%$ \\
\hline
\end{tabular}

Table 5. Distribution between DFI and sperm progressive motility (ICSI procedure)

\begin{tabular}{|c|c|c|c|}
\hline Motility $(\mathrm{a}+\mathrm{b}, \%)$ & $>32 \%$ & $<32 \%$ & Total \\
\hline \multicolumn{4}{|l|}{ DFI $(\%)$} \\
\hline$<26.9 \%$ & $72.36 \%$ & $14.66 \%$ & $87.02 \%$ \\
\hline$>27 \%$ & $9.38 \%$ & $3.61 \%$ & $12.98 \%$ \\
\hline Total & $81.73 \%$ & $18.27 \%$ & $100 \%$ \\
\hline
\end{tabular}

\section{Donation eggs ICSI procedure}

The data were collected from 39 heterologous ICSI donation egg procedures. The mean age of the recipients was $41 \pm 5.22$ years. The pregnancy rate was $55.2 \%$, and $66.7 \%$ clinical pregnancies were achieved. In $33.3 \%$ of the cases, reproductive failures were registered (miscarriages or biochemical pregnancies).

We found no significant difference between DFI and pregnancy rate of heterologous ICSI donation egg procedures $\left(\chi^{2}=1.41 ; p>0.05\right)$ and there was a weak statistical correlation between DFI and pregnancy loss $\left(\chi^{2}=3.49 ; \mathrm{p}<0.05 ; \mathrm{r}=0.25\right.$; $\mathrm{p}=0.03$; Table 6 ).

When examining the impact of sperm parameters on the outcome of ICSI procedures with donated eggs, a statistically significant correlation between sperm morphology and outcome of heterologous ICSI procedures $\left(\chi^{2}=0.50 ; p>0.05\right)$ was not found (Table 7).

Evaluation of percentage of grade I blastocysts (by Gardner and Schoolcraft, 1999) before ET revealed a statistically significant correlation with both DFI $\left(\chi^{2}=7.80 ; \mathrm{p}<0.05\right)$ and sperm morphology $\left(\chi^{2}=6.14 ; \mathrm{p}<0.05\right)$.

There was no statistically significant difference in the percentage of grade I quality blastocysts between autologous and heterologous procedures $(\mathrm{p}>0.05)$.

\section{IUI}

Data about 48 couples undergoing autologous procedure of IUI, and 28 women who underwent insemination with donor sperm (76 treatments altogether) were analyzed.

The average age of the men involved in IUI was $31.08 \pm 7.1$ years, and that of the women was $32.6 \pm 5.5$ years. The oldest female patient was 43 years old.

The pregnancy rate in autologous procedures was $18.18 \%$, and for the IUI donor sperm procedures it was $17.8 \%$. The distribution between DFI and IUI outcome is shown on Table 8.

The highest pregnancy rate was registered in the group aged $36-40$ years $-24.1 \%$. We found no statistically significant relationship between women's age and the IUI success rate $\left(\chi^{2}=2.72\right.$; $\mathrm{p}>0.05$ ).

Regarding the distribution of pregnancy loss rate after IUI procedure no correlation was established with the age of the female patients $\left(\chi^{2}=1.31 ; p>0.05\right)$. In the IUI group, 14 positive tests recorded, of which nine clinical pregnancies ended with delivery $(64.29 \%)$, and miscarriage was registered in five women $(35.71 \%)$. 
When examining the relationship between DFI and IUI outcome (clinical pregnancy, miscarriage) significant correlations were found in both directions: between DFI and pregnancy rate after IUI $\left(\chi^{2}=6.29 ; \mathrm{p}<0.05\right)$ on the one hand, and between the DFI and pregnancy development after IUI, on the other hand $\left(\chi^{2}=6.87 ; \mathrm{p}<0.05\right)$.

Depending on the outcome, the male patients were divided into two groups: fertile and infertile. A statistically significant difference was found between the two groups for sperm concentration $/ \mathrm{ml}(\mathrm{p}<0.01 ;$ Student's t-test $=2.07)$. In the fertile group, the DFI was significantly lower than that in the infertile group $(p<0.05)$. As to the fertile group, the HDS was also significantly lower than that in the infertile patient group $(\mathrm{p}<0.05 ; \mathrm{r}=0.5$; $\mathrm{t}$-test $=1.51)$.

Comparison between DFI in the pairs with clinical pregnancy and those with spontaneous abortion revealed a statistically significant difference $(\mathrm{p}<0.05$; $\mathrm{t}$-test $=1.58)$.

Table 6. Distribution between DFI and pregnancy rate (donation eggs ICSI procedure)

\begin{tabular}{|c|c|c|c|}
\hline $\begin{array}{ll}\mathrm{DFI} \% & \text { ICSI outcome } \\
\end{array}$ & Pregnant & Not pregnant & Total \\
\hline$<26.9 \%$ & $47.3 \%$ & $42.11 \%$ & $89.47 \%$ \\
\hline$>27 \%$ & $7.89 \%$ & $2.33 \%$ & $10.53 \%$ \\
\hline Total & $55.26 \%$ & $44.74 \%$ & $100 \%$ \\
\hline
\end{tabular}

Table 7. Distribution between sperm morphology and pregnancy rate (donation eggs ICSI procedure)

\begin{tabular}{|c|c|c|c|}
\hline $\begin{array}{ll}\text { Morphology (normal forms, \%) } & \text { ICSI outcome } \\
\end{array}$ & Pregnant & Not pregnant & Total \\
\hline$<4 \%$ & $36.84 \%$ & $26.32 \%$ & $63.16 \%$ \\
\hline$>4 \%$ & $18.42 \%$ & $18.42 \%$ & $36.84 \%$ \\
\hline Total & $55.26 \%$ & $44.74 \%$ & $100 \%$ \\
\hline
\end{tabular}

Table 8. Distribution between DFI and IUI outcome

\begin{tabular}{|c|c|c|c|}
\hline $\begin{array}{ll}\text { DFI } & \text { IUI outcome }\end{array}$ & Clinical pregnancy & SPA & Total \\
\hline$<26.9 \%$ & $64.29 \%$ & $14.29 \%$ & $78.57 \%$ \\
\hline$>27 \%$ & $0.0 \%$ & $24.43 \%$ & $21.43 \%$ \\
\hline Total & $64.29 \%$ & $35.71 \%$ & $100 \%$ \\
\hline
\end{tabular}

\section{Discussion}

\section{ICSI}

The mean age of our male and female patients undergoing fertility treatment was higher than 30 . Most of the female patients were 30-35 years old, with a relatively good pregnancy rate. Regarding the number of oocytes retrieved after a long down stimulation protocol, data showed that most of the females fell in the group in which up to 10 eggs per female were retrieved. There was also a negative correlation between the number of oocytes and the age of the patient, as could be expected. The results showed that the highest chance of achieving pregnancy was registered in the group of women from whom 10 to 15 were retrieved. The number of oocytes determined the pregnancy rate. However, no correlation was found between the oocyte number and pregnancy loss rate.

These data suggest a successful model of stimulation to retrieve an optimal number of 10 eggs in order to achieve a high pregnancy rate with ICSI procedure.

The study found no correlation between DFI and registration of pregnancy on day 14 after ET.

Our results confirmed data reported by other researchers [18-20]. The presence of sperm with damaged DNA has a negative impact only on preand post-implantation embryo development [21, 22]. This phenomenon, known as ART bypass, occurs during ICSI procedures with spermatozoa with damaged chromatin. High DFI does not predict successful treatment by ICSI but we found a statistically significant relationship between DFI $>27 \%$ and pregnancy loss. When 
comparing the DFI in fertile and infertile patients in relation to the percentage of grade I blastocysts obtained, no statistically significant correlation was found. This reduction of the pregnancy loss rate after ICSI could be attributed to previous treatment with antioxidants (Lycopene, Astaxanthin) [23].

According to literature data, HDS has no predictive value for success with ICSI [24], which agrees with the data we obtained.

Sperm parameters (concentration, motility, morphology) have no predictive value on ICSI procedure outcome, either. A statistically significant correlation was found with respect to motility and morphology, as compared to the registered pregnancy rate after the ET.

The comparison between fertile and infertile men involved in ICSI procedures showed no significant difference between sperm parameters between the two groups. Probably, conventional sperm parameters reflect functional sperm ability.

Hence, the main conclusion is that choosing the best quality sperm cells is crucial for the success of ICSI procedure. However, this has no influence on events after achieving pregnancy.

No correlation was found between pregnancy rate outcome and sperm parameters and DFI in the group undergoing donation egg procedure. Our results showed an important correlation between DFI and the quality of blastocysts.

The correlation between DFI and occurrence of SPA after heterologous ICSI procedure was weak. These data confirmed the assumption of the leading role of functional properties of the egg in terms of pregnancy outcome in heterologous procedures.

\section{IUI}

Sperm DNA fragmentation has been shown to be an independent predictor of success in couples undergoing intrauterine insemination [25]. According to the Georgetown fertility study [25], the chances of occurrence of pregnancy are greatly reduced in $\mathrm{DFI}>30 \%(\mathrm{OR}=8.0)$. In this study, DFI $>30 \%$ was shown to be associated with the highest rate of spontaneous abortions. The period of pregnancy was shorter in $\mathrm{DFI}<15 \%$. A value of DFI of $20-25 \%$ seems to be a clinically significant threshold for natural conception. Bungum $M$. et al. [26] reported that the IUI success declined in cases of $\mathrm{DFI}>20 \%$ and approached zero when DFI was 30\%. Giwercman [27] believes that for men with poor sperm morphology, the DFI threshold for reduced fertility was $20 \%$.

Our study found a relatively lower success rate of IUI procedures in older females. This also explains the lower success rate in the group with heterologous (donor) procedure. With IUI, a significant correlation was found between the DFI and the procedure outcome as regards registered pregnancies. In relation to miscarriages, HDS was significantly lower in the group of men from couples with registered pregnancy. When comparing DFI between men from couples with clinical pregnancy and those with miscarriages, a significant difference was established.

Of the sperm parameters, only the concentration of $s p e r m / \mathrm{ml}$ proved to be associated with pregnancy rate after IUI.

\section{Conclusions}

It could be concluded that DFI is a predictive factor for ART outcome. DFI can be used as an independent predictor of pregnancy and childbirth in couples undergoing IUI. We can argue that the ICSI procedure allows avoiding failure in case of damaged semen chromatin. High DFI does not exclude successful ICSI, but BP and miscarriages could be of two-fold higher incidence in ICSI procedures when the DFI exceeds $27 \%$.

The three groups of patients undergoing autologous and heterologous ICSI procedures and IUI in our study showed that DFI $>27 \%$ was associated with increased risk of early pregnancy loss.

Infertile males should undergo DNA fragmentation assay in addition to standard semen analysis. When DFI exceeds $27 \%$, ICSI should be a method of choice, even in cases where the conventional parameters of the semen analysis are normal. This study showed that DFI was higher than $27 \%$ in $13 \%$ of the patients.

Concerning HDS, it seems that this parameter had a predictive value only on the IUI outcome.

The biological explanation of the good results after ICSI in cases of high DNA fragmentation needs to be further clarified. In this regard, it could be assumed that donor eggs possess a good capacity for repair in case of sperm DNA fragmentation. Our study showed an increased risk of early pregnancy loss in cases with high levels of DNA fragmentation in ART (ICSI, IUI). High levels of DNA fragmentation are associated with a smaller percentage of blastocysts grade I 
after ICSI. It seems that the choice of morphologically normal and functional quality sperm increases the chances for successful pregnancy. The choice of a low sperm DNA fragmentation provides a high percentage of good quality blastocysts and a successful course of pregnancy.

\section{References}

1. Thonneau P, Marchand S, Tallec A, Ferial ML, Ducot B, Lansac J, et al. Incidence and main causes of infertility in a resident population. Hum Reprod. 1991;6:811-6.

2. Lamb DJ, Lipshultz LI. Male infertility: recent advances and a lоoк toward the future. Curr Opin Urol. 2000;10:359-62.

3. Oehninger S. Clinical and laboratory management of male infertility: an opinion on its current status. JAndrol. 2000;21:814-21.

4. Nagy ZP, Liu J, Joris H, Verheyen G, Tournaye H, Camus $\mathrm{M}$, et al. The result of intracytoplasmic sperm injection is not related to any of the three basic sperm parameters. Hum Reprod. 1995;10:1123-9.

5. Lopes S, Sun J, Jurisicova A, Meriano J, Casper RF. Sperm deoxyribonucleic acid fragmentation is increased in poor-quality semen samples and correlates with failed fertilization in intracytoplasmic sperm injection. Fertil Steril. 1998;69:528-32.

6. Edwards RG, Beard HK. Blastocyst stage transfer: pitfalls and benefits. Hum Reprod. 1999;14:1-6.

7. Ludwig M, Diedrich K. Possibilities and limits of assisted reproduction. Gesundheitswesen. 1999;61:593-600.

8. Sakkas D, Urner F, Bianchi PG, Bizzaro D, Wagner I, Jaquenoud N, et al. Sperm chromatin abnormalities can influence decondensation after intracytoplasmic sperm injection. Hum Reprod. 1996;11:837-43.

9. Irvine DS, Twigg JP, Gordan EL, Fulton N, Milne A, Aitken J. DNA integrity in human spermatozoa: relationships with semen quality. J Androl. 2000;21:33-44.

10. Evenson DP, Jost LK, Marshall D, Zinaman MJ, Clegg E, Purvis K, et al. Utility of the sperm chromatin structure assay as a diagnostic tool in the human fertility clinic. Hum Reprod. 1999;14:1039-49.

11. Larson KL, DeJonge CJ, Barnes AM, Jost LK, Evenson DP. Relationship of assisted reproductive technique (ART) outcomes with sperm chromatin integrity and maturity as measures by the sperm chromatin structure assay (SCSA). Hum Reprod. 2000;15:1717-22.

12. Morris ID, Ilott S, Dixon L, Brison DR. The spectrum of DNA damage in human sperm assessed by single cell electrophoresis (COMET assay) and its relationship to fertilization and embryo development. Hum Reprod. 2002;17:990-8.

13. Saleh RA, Agarwal A, Nelson DR, Nada EA, ElTonsy $\mathrm{MH}$, Alvarez $\mathrm{G}$, et al. Increased sperm nuclear DNA damage in normozoospermic infertile men: a prospective study. Fertil Steril. 2002;78:313-8.

14. Spano M, Bonde JP, Hjollund HI, Kolstad HA, Cordelli E, Leter G. Sperm chromatin damage impairs human fertility. The Danish First Pregnancy Planner Study Team. Fertil Steril. 2000;73:43-50.

15. Zini A, Bielecki R, Phang D, Zenzes MT. Correlations between two markers of DNA integrity, DNA denaturation and DNA fragmentation, in fertile and infertile men. Fertil Steril. 2001;75:674-7.

16. Tomlinson MJ, Moffatt O, Manicardi GC, Bizzaro D, Afnan M, Sakkas D. Interrelationships between seminal parameters and sperm nuclear DNA damage before and after density gradient centrifugation: implications for assisted conception. Hum Reprod. 2001;16:2160-5.

17. World Health Organization. WHO laboratory manual for the examination and processing of human semen. 5th ed. Geneva: World Health Organization; 2010.

18. Sakkas D, Mariethoz, Manicardi G, Bizzaro D,Bianchi U. Origin of DNA damage in ejaculated human spermatozoa. Rev Reprod. 1999;4:31-7

19. Zini A, Garrels K, Phang D. Antioxidant activity in the semen of fertile and infertile men. Urology. 2000;55:922-6.

20. Agarwal A, Prabakaran S, Allamaneni SS. Relationship between oxidative stress, varicocele and infertility: a meta-analysis. Reprod Biomed Online. 2006;12:630-3.

21. Saleh RA, Agarwal A, Nada EA, El-Tonsy MH, Sharma RK, Meyer A, et al. Negative effects of increased sperm DNA damage in relation to seminal oxidative stress in men with idiopathic and male factor infertility. Fertil Steril. 2003;79:1597605.

22. Janny L, Menezo YJ. Evidence for a strong paternal effect on human preimplantation embryo development and blastocyst formation. Mol Reprod Dev. 1994;38(1):36-42.

23. Sikka SC, Rajasekaran M, Hellstrom WJ. Role of oxidative stress and antioxidants in male infertility. J Androl. 1995; 16:464-8.

24. Evenson DP. Sperm chromatin structure assay $\left(\mathrm{SCSA}^{\circledR}\right): 30$ years of experience with the $\mathrm{SCSA}^{\circledR}$. In: Zini A, Agarwal A, editors. Sperm chromatin: Biological and clinical applications in male infertility and assisted reproduction. New York: Springer; 2011. p. 125-49.

25. Zinaman MJ, Brown CC, Selevan SG, Clegg ED. 
Semen quality and human fertility: a prospective study with healthy couples, J Androl. 2000;21(1):145-53.

26. Bungum M, Humaidan P, Axmon A, Spano M, Bungum L, Erenpreiss J, et al. Sperm DNA integrity assessment in prediction of assisted reproduction technology outcome. Hum Reprod
[Internet]. 2007;22(1):174-9. Available from: http://humrep.oxfordjournals.org/content/22/1/17 4.short - aff-1.

27. Giwercman A, Lindstedt L, Larsson M, Bungum M, Spano M, Levine RJ, et al. Sperm chromatin structure assay as an independent predictor of fertility in vivo: a case-control study. Int J Androl. 2010;33(1):e221-7. 